\title{
Effects of high-intense resistance training on salivary cortisol in trained individuals: a systematic review \\ Efectos del entrenamiento de resistencia de alta intensidad sobre el cortisol salival en individuos entrenados: una revisión sistemática
}

*Rogério Santos de Aguiar, *Gustavo Casimiro Lopes, *Juliana Brandão Pinto de Castro, *Vitor Ayres Prince,

**Mauro Lúcio Mazini Filho, *Dirceu Ribeiro Nogueira da Gama, *Rodolfo deAlkmim Moreira Nunes,

* Jomilto Luiz Praxedes dos Santos, *,***Rodrigo Gomes de SouzaVale

*Universidade do Estado do Rio de Janeiro (Brasil), **Universidade Federal de Juiz de Fora(Brasil), ***U niversidade Estácio de Sá (Brasil)

\begin{abstract}
This study aimed to evaluate the effects of high-intensity training (HIT) on salivary cortisol levels in physically trained individuals. This systematic review followed the Preferred Reporting Items for Systematic Reviews and M etaAnalyses (PRISMA) recommendations. The search for scientific articles was carried out on the Scopus and MED LINE (via PubM ed) databases with the terms resistancetraining, saliva, cortisol, and their synonyms.Weincluded interventionswith high-intense resistancetraining that analyzed the salivary cortisol levels in physically trained men and women. From the 399 articles found, eight studies met the inclusion criteria. A population of 135 physically trained men and 12 women is with an average age of $23.26 \pm 3.10$ years, body mass of $85.53 \pm 12.68$ $\mathrm{kg}$, and height of $1.80 \pm 0.04 \mathrm{~m}$. The intervention period ranged from 3 to 15 weeks with the use of 1 to 5 sets of 5 to 10 repetitions. M ost protocols have been shown to provide significant stimuli to increase the level of cortisol acutely $(p<0.05)$. The practice of HIT seems to be an effective intervention to stimulate the increase in acute and chronic salivary cortisol levels and thus induce possible changes in physiological and hormonal levels. Moreover, cortisol seems to represent physical activity in some populations and may be useful in monitoring physiology in large-scal e observational physical activity surveys. However, more research is needed to elucidatethe effects of HIT on cortisol and adaptive results.
\end{abstract}

Keywords: Resistancetraining, Saliva, Cortisol.

Resumen. Esteestudio tuvo como objetivo evaluar los efectos del entrenamiento dealtaintensidad sobre losniveles de cortisol salival en individuos entrenados físicamente. Esta revisión sistemática siguió las recomendaciones de PRISMA. La búsqueda de artículos científicosse realizó en lasbasesScopus y M ED LINE (víaPubM ed) con los términosentrenamiento de resistencia, saliva, cortisol y sus sinónimos. Se incluyeron intervenciones con entrenamiento de resistenciade altaintensidad queanalizaron losnivelesde cortisol salival en hombres y mujeres entrenadosfísicamente. De los 399 artículos encontrados, ocho estudios cumplieron los criterios de inclusión. Unapoblación de 135 hombresentrenadosfísicamentey 12 mujerestieneunaedad de23,26 $\pm 3,10$ años, masacorporal de85,53 $\pm 12,68$ kg y altura de 1,80 $\pm 0,04 \mathrm{~m}$. El período de intervención varió de 3 a 15 semanas con el uso de 1 a 5 seriesde 5 a 10 repeticiones. Seha demostrado que la mayoría de los protocolos proporcionan estímulos significativos para aumentar el nivel de cortisol de forma aguda $(p<0,05)$. Laprácticadeentrenamiento dealtaintensidad pareceser unaintervención eficaz paraestimular el aumento delosnivelesde cortisol salival agudo y crónico y así inducir posibles cambios en los niveles fisiológicos y hormonales. Además, el cortisol parece representar la actividad física en algunas poblaciones y puede ser útil para monitorear la fisiología en encuestas observacionales de actividadfísicaagran escala. Sin embargo, senecesitamásinvestigación paradilucidar losefectosdeentrenamiento dealtaintensidad sobre el cortisol y los resultados adaptativos.

Palabras clave: Entrenamiento de resistencia, Saliva, Cortisol.

\section{Introduction}

Resistance exercises, especially those performed at high intensity, cause significant endocrine changes, both acute and chronic in an effective stimulus for the hypothalamic-pituitary-adrenal axis, resulting in a significant increase in circulating cortisol levels (Becker

Fecha recepción: 18-08-20. Fecha de aceptación: 21-12-20

Rogério Santos Aguiar

rogghi@gmail.com et al., 2020; W ilk et al., 2018a).

Cortisol is a glucocorticoid secreted by the adrenal cortex of the adrenal glands and exerts many beneficial effects in humans, increasing the availability of metabolic substrates, maintaining normal vascular integrity, and protecting the body from an exaggerated response of the immune system to exercise-induced muscle damage (Becker et al., 2020; Vale et al., 2012). Cortisol plays important roles during and after exercise, including participating in gluconeogenesis and accelerating the mobilization and use of fats for energy production 
(Becker et al., 2020; Vale et al., 2012).

Cortisol levels increase at a relatively proportional rate in response to high-intensity training (HIT). Depending on the characteristics of stimuli, these responses can be classified as acute and chronic (Bonato et al., 2017). For these reasons, the HIT can be used to promote an increase in salivary cortisol levels and determine acute physiological stress (Ciolac $\&$ Silva, 2016).

These changes can induce, in athletes and physically trained individuals, an adaptive response to mechanical stress caused by weight resistance, which can promote increases in muscle mass, muscle strength and hypertrophy due to HIT. During training sessions, many catabolic actions occur (AC SM , 2017; A razi et al. , 2019; Bonato et al. , 2017). These catabolic actions can generate tissue damage necessary to muscle fibers so that the cell regeneration process occurs in greater proportions during the rest period, after the training sessions. This can stimulate the gains of hypertrophy and muscle strength (Arazi et al., 2019; Crewther et al., 2011).

Therefore, HIT can promote an acute increase in cortisol secretion, which plays a role in stimulating glycogenesis, accelerating and mobilizing free fatty acids, and initiating glucose maintenance (Anderson et al., 2016). There may be an increase in metabolic response, which can be evidenced by decreased $\mathrm{pH}$ and increased lactate concentrations (Geisler et al., 2019). This can occur due to the high volume of training and intensity and short intervals of muscle recovery between the sets of exercises (Church et al., 2016). Thus, there are greater stimuli in type II muscle fibers, which are responsible for higher production of strength, power, and speed (Raya-González et al., 2018).

Cortisol acts as a physiological antagonist of insulin because it promotes the breakdown of carbohydrate, lipid, and protein molecules. Generally, salivary cortisol has been used to study the chronic and acute effects of training in place of blood test analysis, which is more invasive and causes discomfort in trained individuals or athletes (W unsch et al., 2019).

The salivary cortisol collection is a method that involves a simple procedure that does not produce enough changesto significantly interfere with the results. Because it is a non-invasive technique, the collection is not stressful, unlike venous puncture, which many consider painful (Vale et al., 2012). This collection procedure allows an adequate analysis and prediction of cortisol levels in response to the intervention (Pineda Espejel et al., 2020).

Thus, this systematic review aimed to evaluate the effects of HIT on salivary cortisol levels in physically trained individuals.

\section{M ethods}

This systematic literature review followed the Preferred Reporting Items for Systematic Reviews and Meta-A nalyses (PRISMA) guidelines (Liberati et al., 2009).

\section{Eligibility aiteria}

Table 1 shows the PICO S strategy used to del imitate the inclusion criteria. We excluded review studies, studies with animals or diseases, studies with other populations, and studies that used aerobic training as intervention.

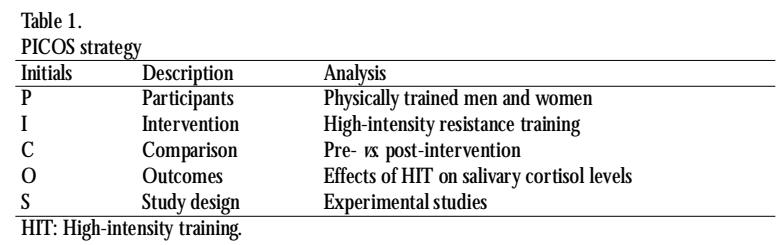

\section{Search strategy}

A systematic search was performed without time or language filters in the electronic databases Scopus and M edLine (via PubM ed), with last updated in April 2020. We used the descriptors «resistance training», «Saliva», and «cortisol» and their synonyms, available at Health SciencesDescriptors (DeCS) and M edical Subject Headings (M eSH). The search was performed with the Boolean operators [OR] (between synonyms) and [AND] (between descriptors). We checked the references of the selected studies and other sources to maximize the search.

After the references were extracted using the search terms, they were exported to a shared library on M endeley Desktop. Two authors completed the research, the removal of duplicates, the analysis of titles and abstracts, and the screening of the complete articles. Any differences in the analysis were sent to a third author. Then, we read the full version of the articles assessed for eligibility and those that did not meet the inclusion/ exclusion criteria were removed.

\section{Bias analyeis}

The Risk of Bias In Non-randomized Studies - of Interventions (ROBINS-I) tool was used to assess the risk of bias in the studies included in this systematic review (Sterne et al., 2016). Two independent and experienced evaluators analyzed the risk of bias in the included studies. Disagreeing assessments were solved 
by a third researcher.The studies were classified as «selection bias», «performance bias», «detection bias», «follow-up bias», «report bias», «lack of data bias», and «bias in result selection reported», and were evaluated in the domains «yes», «Probably yes», «Probably not», and «No». Responses of «Yes» and «No» are intended to have similar implications to responses of «Probably yes» and «Probably no», respectively. Each «Yes» or «Probably yes» corresponds to 1 point. The scores of the sum of the seven domains are: one or two points = severe risk of bias, three or four points $=$ moderate risk of bias, and five to seven $=$ low risk of bias.

\section{Results}

In total, 399 studies were found following the proposed research methodology. After using the selection criteria, eight articles were included in this review (Figure 1).

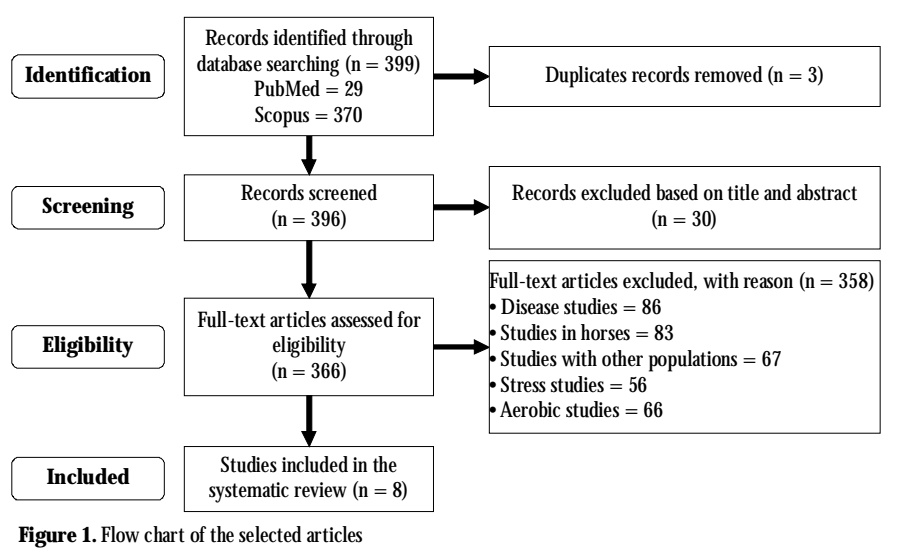

Table 2 presents the characteristics of the eight included studies. The total number of participants was 147 physically trained individuals (135 men and 12 women), with an average age of $23.26 \pm 3.10$ years, body mass of $85.53 \pm 12.68 \mathrm{~kg}$, and height of $1.80 \pm$ $0.04 \mathrm{~m}$.

\begin{tabular}{|c|c|c|c|c|c|}
\hline \multirow{2}{*}{ Authors/year } & \multirow{2}{*}{ Country } & \multirow{2}{*}{ Sample } & \multicolumn{3}{|c|}{ Population characteristics } \\
\hline & & & Age (years) & Height (m) & Body mass (kg) \\
\hline Ander son et al. (2016) & USA & $20 M$ & $19.1 \pm 1.1$ & $1.85 \pm 6.7$ & $102.0 \pm 22.2$ \\
\hline Bartolomei et al. (2014) & Italy & $18 \mathrm{M}$ & $26.0 \pm 7.8$ & $1.77 \pm 0.05$ & $78.7 \pm 0.28$ \\
\hline Cintineo et al. (2018) & USA & $19 M$ & $21.11 \pm 2.5$ & $174.33 \pm 6.83$ & $76.72 \pm 10.24$ \\
\hline Gaviglio et al. (2015) & England & $27 \mathrm{M}$ & $28.3 \pm 4.0$ & $1.87 \pm 0.08$ & $107.6 \pm 18.9$ \\
\hline Geisler et al. (2019) & Germany & $13 \mathrm{M}$ & $23.4 \pm 1.3$ & $1.82 \pm 5$ & $81.8 \pm 6.4$ \\
\hline Genner and Weston (2014) & USA & $12 \mathrm{M}$ & $25.4 \pm 6.9$ & $1.80 \pm 7$ & $77 \pm 10$ \\
\hline Sinclair et al. (2013) & England & $12 \mathrm{M}$ and $12 \mathrm{~W}$ & $22 \pm 0.71$ & $1.78 \pm 8.4$ & $73.15 \pm 6.9$ \\
\hline Weakley et al. (2017) & England & $14 \mathrm{M}$ & $20.8 \pm 1.2$ & $1.81 \pm 0.06$ & $87.3 \pm 6.2$ \\
\hline
\end{tabular}

Table 3.

Methods and outcomes of the studies included in this review

\begin{tabular}{|c|c|c|c|c|c|c|}
\hline Studies & Test & $\begin{array}{l}\text { Load, in kg } \\
(\text { Mean } \pm \text { SD) }\end{array}$ & Exercise & $\begin{array}{l}\text { Intervention } \\
\text { period }\end{array}$ & $\begin{array}{c}\text { Cortisol result } \\
(\text { Mean } \pm \text { SD) }\end{array}$ & $p$-value \\
\hline $\begin{array}{l}\text { Anderson et al. } \\
(2016)\end{array}$ & 1RM & $145.45 \pm 26.87$ & $\begin{array}{l}\text { Bench press } \\
\text { Squat clean }\end{array}$ & $\begin{array}{c}12 \\
\text { weeks }\end{array}$ & $\begin{array}{l}\uparrow 5.33 \pm 4.94 \\
\uparrow 2.57 \pm 2.46\end{array}$ & $p<0.05$ \\
\hline $\begin{array}{l}\text { Bartolomei et al. } \\
\text { (2014) }\end{array}$ & 1RM & $118.45 \pm 25.69$ & $\begin{array}{l}\mathrm{BS}+\mathrm{BP}+\mathrm{DPB}+\mathrm{D}+ \\
\mathrm{SC}+\mathrm{TPD}+\mathrm{PBR}+\mathrm{L} \\
\mathrm{M}+\mathrm{PU}+\mathrm{DR}+\mathrm{SBC} \\
+\mathrm{PC}+\mathrm{LP}+\mathrm{LE} / \mathrm{LC} \\
+\mathrm{MP}+U R+\mathrm{LL}+\mathrm{IB} \\
\mathrm{P}+\mathrm{LR}+\mathrm{PLL}+\mathrm{IDC}+\end{array}$ & $\begin{array}{c}15 \\
\text { weeks }\end{array}$ & $\begin{array}{c}\uparrow B P+19.0 \% \\
\uparrow W W P+21.3 \%\end{array}$ & $\begin{array}{l}p<0.05 \\
p<0.05\end{array}$ \\
\hline
\end{tabular}

\begin{tabular}{llllll}
\multicolumn{7}{c}{$P C$} \\
\hline Cintineo et al. & 10RM & NR & LP+LE+RD +ILC+ 2 & $\uparrow H I T=0.3 \pm 0.1$ & $p<0.01$
\end{tabular}

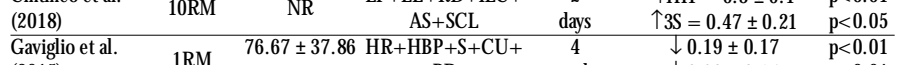
\begin{tabular}{cccccc} 
(2015) & IRM & PR & weeks & $\downarrow 0.20 \pm 0.15$ & $p<0.01$ \\
\hline & & 3 & & $11 \mathrm{~mm}$ &
\end{tabular}

$\begin{array}{llllcll}\text { Geisler et al. } & \text { 1RM } & 109.75 \pm 15.75 & \begin{array}{c}\text { Back-squat } \\ \text { HBP }\end{array} & 3 & \uparrow 11 \mathrm{mmol} / \mathrm{L} & p<0.05\end{array}$

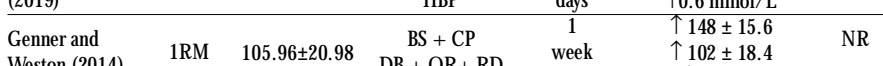

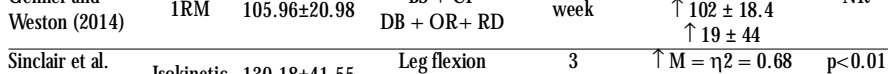

\begin{tabular}{|c|c|c|c|c|c|}
\hline $\begin{array}{l}\text { Sinclair et al. } \\
\text { (2013) }\end{array}$ & Isokinetic & $130.18 \pm 41.55$ & $\begin{array}{l}\text { Leg flexion } \\
\text { Leg extension }\end{array}$ & $\begin{array}{c}3 \\
\text { weeks }\end{array}$ & $\begin{array}{l}T M=\eta 2=0.68 \\
\downarrow W=\eta 2=0.25\end{array}$ \\
\hline
\end{tabular}

$\begin{array}{llllll}\text { Weakley et al. } \quad 3 R M \quad 471.6 \pm 191.02 & \mathrm{HBP}+\mathrm{RD}+\mathrm{DSP}+ & 4 & \downarrow \mathrm{TRAD}=0.10 \pm 0.07 & \mathrm{NR}\end{array}$

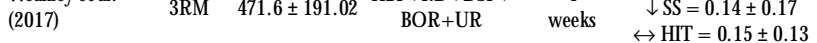

SD: Standard deviation, RM: repetition maximum, WWP: Weekly wavy periodization, BP: bench press, DBP: Dumbell bench press, D: Dips, SC: Skull crushers, TPD: Triceps pull down, PBR: Prone barbell row, LM: Lat machine, PU: Pull up, DR: D umbell row, SBC: Standing barbell curl, PC: Preacher curl, BS: Back squat, LP: Leg press, LE: Leg extension, LC: Leg curl, MP: Military press, UP: Upright row, LL: Lateral lift, IBP: Inclined bench press, LR: Low row, PLL: Prone lateral lifts, IDC: Inclined dumbell curl, PC: Preacher curl, BS: Back squat, CP: Chest press, BD: Bench press, DSP: Dumbbell shoulder press, UR: U pright row, BOR: Bent over row, CU: Chinups, PR: Prone row, HR: High pull, RD: Romanian deadlift, ILC: Inclined leg curl, AS: Adductor seated, SCL: Seated calf lift, LFE: Leg flexion and extension, TRAD: Traditional, SS: Superset, HIT: High-intensity training

$R:$ Not reported, M: men;W: women, $\uparrow$ increase, $\downarrow$ decrease, $\leftrightarrow$ maintenance.

Table 3 shows the methods and the main outcomes of the studies included in this review. Of the eight studies, seven used the maximum repetition test (RM) (Anderson et al., 2016; Bartolomei et al., 2014; Gaviglio et al., 2015; Geisler et al., 2019; Genner $\&$ Weston, 2014; Weakley et al. , 2017) and one used the isokinetic device (Sinclair et al., 2013). Two studies showed a decrease in cortisol levels (Genner \& Weston, 2014; Weakley et al., 2017). Two other studies (Sinclair et al. , 2013; Anderson et al., 2016) showed an increase and decrease. O ne study (Sinclair et al., 2013) showed an increase in cortisol levels in men and a decrease in women. 0 ne study (Anderson et al., 2016) showed an acute increase in salivary cortisol levels after the first intervention and a chronic increase after 12 weeks. Three experiments (Bartolomei et al., 2014; Geisler et al., 2019; Genner \& Weston, 2014) showed sharp increases in cortisol levels after the intervention.

Table 4 shows the studies' risk of bias through the ROBINS-I tool. According to this tool, one study 
(Anderson et al., 2016) was considered with a serious risk of bias, four studies (Bartolomei et al. , 2014; Geisler et al., 2019; Genner \& Weston, 2014; Sinclair et al., 2013) showed a moderate risk of bias, and three studies (Cintineo et al. , 2018; Gaviglio et al. , 2015; Weakley et al., 2017) presented a low risk of bias.

\section{Discussion}

This review aimed to investigate the effects of highintense resistance training on salivary cortisol levels in physically trained individuals. Of the eight studies, seven used HIT in interventions in traditional bodybuilding machines and or free weights (Anderson et al., 2016; Bartolomei et al. 2014; Cintineo et al., 2018; Gaviglio et al., 2015; Geisler et al., 2019; Genner $\&$ Weston, 2014; Weakley et al., 2017) and one study used the isokinetic device (Sinclair et al., 2013).

The analysis of the included studies showed that the practice of HIT, with protocols of exercises performed in two or fifteen days, caused a significant response to cortisol during exercise and recovery. Additionally, the eight studies demonstrated that proper manipulation of all protocols and variables is crucial to obtain these responses after 2 to 15 weeks of HIT due to the o high volume of training

The endocrine system is particularly sensitive to resistance exercises and changes in anabolic and catabolic hormonesand has been associated with the post-exercise reconstruction process of damaged muscle cells and, therefore, the magnitude and the taxed post-exercise adaptation (W ilk et al., 2018a).

It is important to note that five studies (Anderson et al., 2016; Bartolomei et al., 2014; Cintineo et al., 2018; Geisler et al., 2019; Genner \& Weston, 2014) showed that, after the HIT intervention, there was a chronic increase in musclestrength and an acuteincrease in cortisol levels, and two studies (Gaviglio et al., 2015; Weakley et al., 2017) showed a chronic decrease in cortisol levels after the intervention. In these two studies, it seems that the ideal volume and intensity of the training loads can stimulate catabolic hormones more effectively and this was not determined. This may be due to several factors such as the speed of movement for an exercise, age, gender, training experience, type of muscle contractions used that complicate this problem. Additional factors include equipment type, diet, supplementation, and how these factors interact with a genetic endowment (W ilk et al., 2018b).

Another study (Sinclair et al., 2013) showed an acute increase in cortisol levels in men and a decrease in women post-intervention. This study (Sinclair et al., 2013) performed the intervention in the morning, afternoon, and evening, to verify the influence of circadian rhythms on metabolic cortisol response acutely in 12 men and 12 women aged between 21 and 22 years. Saliva samples were collected at three different times: in the morning (collection 1), in the afternoon (collection 2), and in the evening (collection 3), in three sessions separated for seven days. The authors reported that the investigation showed circadian variation in the acute increase in cortisol level after the intervention in the afternoon and evening in men and the lowest level in women in the morning.

These results are in agreement with Parastesh et al. (2019), who investigated the effect of salivary cortisol in the morning, in 15 young athletes after an intense exercise session. According to the results found, there wasno increase in salivary cortisol level in young athletes after the intervention. This showed that the intervention period in the women studied caused low stress to stimulate an increase in cortisol level. As a final product, cortisol acts negatively, suppressing activity in the hippocampus and pituitary gland.

The findings of Sinclair et al. (2013) confirm the results of Teo et al. (2011) when investigating the effect of circadian rhythm on cortisol in 20 men with 23 years, in four sessions of resistance exercise. The hormonal response induced by strength tests showed a significant increase in acute cortisol levels in the afternoon and evening. On the other hand, Radaelli et al. (2015), Cintineo et al. (2018), and Berelleza et al. (2020) concluded that HIT may increase short-term adaptive responses in the short term of hypertrophic and strength due to increased cortisol concentrations and that this occurs only when appropriate intensity thresholds are reached in the hypothalamus-pituitary-adrenal (HPA).

Weakley et al. (2017) examined the influence of three training methods on hormonal responses. The individuals were randomly divided into three groups, submitted to simple methods of series, superset, and tri-set. The authors describe that the group submitted to the superset method showed a significant increase in cortisol levels in response to acute and chronic stress compared to the groups submitted to tri-set methods and simple series. The results obtained in this study suggest that the super defined method promoted a more favorable environment for anabolism after four weeks of intervention.

Cintineo et al. (2018) evaluated acute hormonal 
responses in a single high-intensity eccentric training and a traditional 3-sets protocol. Participants were randomly divided into two training groups of three sets (3TS; $n=9$ ) and another HIT group (HIT; $n=10$ ) using a computer-generated resource list of numbers. The reports in this study showed that the 3TS and HIT groups obtained a significant increase in cortisol levels after the intervention. Nevertheless, the 3TS group showed a more robust level of cortisol. This may have run due to longer time on muscle group tension, generating the potentially unique effects of acute biochemical data volume, and physiological and hormonal responses.

Cintineo et al. (2018) observed that cortisol response increased during exercise and post-exercise and remained elevated for 30 minutes after exercise in the 3ST group, while the HIT group showed no change in cortisol in relation to baseline at any time. This is due to the training volume was higher in the 3ST group than in the HIT group. The results of this study also indicate that the amount of induced metabolic stress was higher in the 3ST protocol compared to the HIT protocol.

This is consistent with the findings of Klemp et al. (2016), showing that one set and 3 sets resistance training protocol causesamore robust responseto cortisol during exercise and recovery compared to a single set protocol. On the other hand, W ilk et al. (2018a) found that acute cortisol can regulate long-term changes in muscle strength and hypertrophy, especially due to HIT volume.

These changes in cortisol concentrations can moderate or support the performance capacity of the neuromuscular system through several short-term mechanisms, including gluconeogenesis stimulation and glycogen synthesis in the liver and its ability to inhibit protein synthesis and stimulate protein degradation in peripheral tissues and muscle properties (Adebero et al., 2019).

M angine et al. (2016) reported that the HIT method promotes effect and adaptation in the human neuromuscular system in the manipulation of training variables, number of sets, intensity, recovery intervals, muscle contraction speed, and exercise order. Thus, it can induce possible acute changes in physiological and hormonal levels, offering short-term neuromuscular adaptation for energy performance and, in thelong term, muscle strength and hypertrophy (Crewther \& Christian, 2010).

Similarly, two experimental studies (Geisler et al., 2019; Genner \&Weston, 2014) used HIT exclusively as an inter vention and found significant acute and chronic increases in salivary cortisol levels concentrations $(p<0.05)$. To Crewther and Christian (2010), this hormonal response after HIT intervention is due to an adaptation to training, partly due to individual variation in response to strength exercise, hypertrophy, and longterm, and, in the short term, to the neuromuscular system in trained individuals.

Hence, W ilk et al. (2018a) state that changes in endogenous hormonal cortisol may have different responses in training for highly trained individuals in the short term and the lack of any change may reflect as an adaptation to training Thus, the different responses of cortisol may play important roles in mediating the adaptation of training with one or more mechanisms involved, such as muscle and motor unit development, emotional and behavioral changes, and mobilization of metabolic resources (Crewther et al., 2016).

Thus, highly trained individuals may also have ideal neuromuscular profiles to promote short-term effects on cortisol, as they have a larger type II transverse muscle area and a higher percentage of type II fibers compared to trained individuals (Crewther et al ., 2011; Geisler et al., 2019). However, this relation may be better detected on an individual level among the populations of trained individuals, but with two important observations. First, these relationships may depend on the subject's strength levels or training experience. Second, its detection (or lack thereof) may also reflect the analytical approach and whether individual differences or changes are compared (Crewther et al., 2012). Addressing these issues within the same structure would provide a greater understanding of the role of cortisol in mediating adaptations in athletic populations and trained individuals (Crewther et al., 2016).

This review has limitations that should be highlighted. The analyzed studies did not perform long periods of saliva collection after interventions to obtain better insights on the process of change in the hormonal level and the salivary cortisol levels after physical stress. Another factor is that the results of these studies are only based on samples of trained individuals. In addition, it should also be noted the lack of information on the methodologies on the accuracy and reproducibility used in the studies. Furthermore, restrictions in the search strategy may have caused a loss of information available in the scientific literature. Thus, the findings of this review should be analyzed with caution and critical reading of the outcomes must 
be carried out.

\section{Conclusion}

HIT appears to be an effective intervention to stimulate increased acute and chronic salivary cortisol levels and thus induce possible changes in physiological and hormonal levels. However, from the limited evidence presented in this review, cortisol appears to be a viable biomarker for monitoring HIT responses and health-related outcomes. In particular, it appears that cortisol may be influenced by an intensity limit since changes in cortisol seem to occur in inter ventions of a higher training volume in those who presumably have a reduced training tolerance. M oreover, cortisol seems to represent physical activity in some populations and may be useful in monitoring physiology in observational large-scale physical activity research. However, more research is needed to elucidate the effects of cortisol on HIT performance and adaptive results.

\section{References}

Adebero, T., McKinlay, B. J., Theocharidis, A., Root, Z., Josse, A. R., Klentrou, P., \& Falk, B. (2020). Salivary and serum concentrations of cortisol and testosterone at rest and in response to intense exercise in boys versus men. Pediatric Exercise Science, 32 (2), 65- 72. https:/ / doi.org/ 10.1123/ pes 2019-0091

American College of Sports M edicine. (2017). ACSM 's guidelines for exercise testing and prescription. 10th ed. Philadelphia: Wolters Kluwer/ Lippincott W illiams \& Wilkins.

Anderson, T., Haake, S., Lane, A. R., \& Hackney, A. C. (2016). Changes in resting salivary testosterone, cortisol and interleukin- 6 as biomarkers of overtraining Baltic Journal of Sport \& Health Sciences, 101(2), 2-7.

Arazi, H., Eghbali, E., Suzuki, K., \& M ahdavi, M. (2019). Resistance exercise on two consecutive days induces cortisol, CK, IgA responsesinactiveyoung males Apunts. M ediana del'Esport, 54 (204), 131-138. https:/ / doi.org/ 10.1016/ j.apunts. 2019.11.001

Bartolomei, S., Hoffman, J. R., Merni, F., \& Stout, J. R. (2014).A comparison of traditional and block periodized strength training programs in trained athletes. Journal of Strength and Conditioning Research, 28(4), 990-997. http:/ / doi.org/ 10.1519/ JSC.0000000000000366

Becker, L., Semmlinger, L., \& Rohleder, N. (2020). Resistance training as an acute stressor in healthy young men: associations with heart rate variability, alpha amylase, and cortisol levels. International Journal on the Biology of Stress, 3, 1-13. http:/ / doi.org/ 10.1080/ 10253890.2020 .1799193

Berelleza, R. G., Trejo, M. T., Román, J. C. B., Alarcón Meza, E., Espejel, H. P., Millan, E. A., Hernández, G. S. R., \& Riveros, L. C. (2020). Effect of astrength training program on IGF-1 in older adults with obesity and controlled hypertension. Retos, 39, 253-256. https:/ / doi. org/ 10.47197/ retos. v0i39.74723

Bonato, M., LaTorre, A., Saresella, M., Marventano, I., Merati, G., \& Vitale, J. A. (2017). Salivary cortisol concentration after high-intensity interval exercise: T ime of day and chronotype effect. Chronobiology International, 34(6), 698-707. https:// doi. org/ 10.1080/ 07420528.2017 .1311336

Church, D. D., Hoffman, J. R., Mangine, G. T., Jajtner, A. R., Townsend, J. R., Beyer, K. S., et al. (2016). Comparison of high-intensity vs, high-volume resistance training on the BDNF response to exercise. Journal of Applied Physiology, 121(1), 123-128. https:/ / doi.org/ 10.1152/ japplphysiol.00233.2016

Cintineo, H. P., Freidenreich, D. J., Blaine, C.M., Cardaci, T.D., Pellegrino, J. K., \& Arent, S. M. (2018). Acute physiological responses to an intensity-and time-undertension-equated single- vs. Multiple-set resistance training bout in trained men. Journal of Strength and Conditioning Research, 32(12), 3310-3318. https:// doi:10.1519/ JSC.0000000000002872

Ciolac, E. G., \& Silva, R. J. M. (2016). Resistancetraining as a tool for the prevention and treatment of musculoskeletal disorders. Sports M edicine, 46(9), 12391248. https:/ / doi.org/ 10.1007/ s40279-016-0507-Z

Crewther, B. T., \& Christian, C. (2010). Relationships between salivary testosteroneand cortisol concentrations and training performance in 0 lympic weightlifters. Journal of Sports M edicine and Physical Fitness, 50(3), 371375.

Crewther, B.T., Cook, C., Cardinale, M., Weatherby, R. P., \& Lowe, T. (2011). Two emerging concepts for elite athletes. Sports M edicine, 41(2), 103-123. https:/ / doi.org/ 10.2165/ 11539170-000000000-00000

Crewther, B.T., Cook, C. J. , Gaviglio, C. M., Kilduff, L. P., $\&$ Draver, S. (2012). Baseline strength can influence the ability of salivary free testosterone to predict squat and sprinting performance. Journal of Strength and Conditioning Ressearch, 26(1), 261-268. https:/ / doi.org/ 10.1519/ JSC.0b013e3182185158

Crewther, B. T., Heke, T., \& Keogh, J. (2016). The effects of two equal-volumetraining protocolsupon strength, body 
composition and salivary hormones in male rugby union players. Biology of Sport, 33(2), 111-116. https:/ / doi.org/ 10.5604/20831862.1196511

Gaviglio, C. M., Kelly, V. G., Kilduff, L. P., \& Cook, C. J. (2015). Salivary testosterone and cortisol responses to four different rugby training exercise protocols. European Journal of SportsScience, 15(6), 497-504. https:/ / doi.org/ 10.1080/ 17461391.2015.1017012

Geisler, S., Aussieker, T., Paldauf, S., Scholz. S. Kur, Z. Jungs, S., Rissmeyer, M., Achtzehn, S., \& Zinner, C. (2019). Salivary concentrations of testosterone and cortisol after two differentresistance training exercises. Journal of Sports M edianeand Physical Fitness, 59(6), 1030-1035. https: / / doi.org/ 10.23736/ S0022-4707.18.08786-8

Genner, K. M., \& Weston, M. (2014). A comparison of workload quantification methods in relation to physiological responses to resistance exercise. Journal of Strength and Conditioning Research, 28(9), 2621-2627. https:/ / doi.org/ 10.1519/ JSC.0000000000000432

Klemp, A., Dolan, C., Q uiles, J. M., Blanco, R., Zoeller, R. F., Graves, B. S., \& Zourdos, M. C. (2016). Volumeequated high- and low-repetition daily undulating programming strategies produce similar hypertrophy and strength adaptations. Applied Physiology, N utrition, and Metabolism, 41(7), 699-705. DO I: https:/ / doi.org/ 10.1139/ apnm-2015-0707

Liberati,A., Altman, D. G., Tetzlaff, J. M ulrow, C., Gøtzsche, P. C., Ioannidis, J. P. A., et al. (2009). The PRISMA statement for reporting systematic reviews and meta analyses of studies that evaluate healthcare interventions: explanation and elaboration. British M edical Journal, 339, b2700. https:/ / doi.org/ 10.1136/ bmj.b2700

Parastesh, M., Jalali, S. H., \& Moradi, J. (2019). The effect of circadian rhythm on blood lactate concentration and salivary cortisol after one session of exhausting exercise in athlete girls. Razi Journal of M edical Sciences, 26(9), 59-67. http:/ / rjmsiums. ac. ir/ article-1-5477-en. html

PinedaEspejel, H., Trejo, M., García, K., Garza, K., Vázquez-Jiménez, G., Machado-Contreras, J., M ejía León, M., \& Rodríguez, S. (2019). Salivary cortisol response and precompetitive anxiety in swimmers, Re tos, 38(38), 1-7. https:// doi.org/ 10.47197/ retos. v38i38.72229

Radæelli, R., Fleck, S. J., Leite, T., Leite, R. D., Pinto, R. S., Fernandes, L., \& Simão, R. (2015). Dose-response of 1, 3 , and 5 sets of resistance exercise on strength, local muscular endurance, and hypertrophy. Journal of Strength and Conditioning Research, 29(5), 1349-1358. https:/ / doi.org/ 10.1519/ JSC.0000000000000758

Raya-González, J., Suárez-Arrones, L., Rísquez Bretones,
A., \& Sáez deVillarreal, E. (2017). Short-term effects of an eccentric-overload training program on the physical performance on U-16 elite soccer. Retos, 33, 106- 111. https: / / doi.org/ 10.47197/ retos. v0i33.53547

Sinclair, J., W right, J., Hurst, H. T., Taylor, P. J., Atkins, S. (2013). The influence of circadian rhythms on peak isokinetic force of quadriceps and hamstring muscles. Isokinetics and Exercise Science, 21(4), 279-284. https:/ / doi.org/ 10.3233/ IES-130498

Sterne, J. A. C., Hernán, M. A., Reeves, B. C., Savoviæ, J., Berkman, N. D.,Viswanathan M., etal. (2016). RO BINSI: atool for assessing risk of biasin non-randomised studies of interventions. British M edical Journal, 355, i4919. https:/ / doi.org/ 10.1136/ bmj.i4919

Teo, W., M cguigan, M. R., \& Newton, M. J. (2011). The effects of circadian ritmetics of salivary cortisol and testosteroneon maximum isometric strength, maximum dynamic strength and energy output. Journal of Strength and Conditioning Reserch, 25, 1538-1545. https: / / doi.org/ 10.1519/ jsc.0b013e3181da77b0

Vale, R. G. S., Rosa, G., Nodari Junior, R. J., \& Dantas, E. H. M. (2012). Cortisol and physical exercise In: Esposito, A. , \& Bianchi,V. (O rgs.). Cortisol: physiology, regulation and health implications. N ew York: Nova Science Publishers.

Weakley, J. J. S., Till, K., Read, D. B., Roe, G. A. B., DarralJones, J., Phibbs, P. J., et al. (2017). The effects of traditional, superset, and tri-set resistance training structures on perceived intensity and physiological responses. European Journal of Applied Physiology, 117, 18771889. https:/ / doi.org/ 10.1007/ s00421-017-3680-3

W ilk, M., Petr, M., Krzysztofik, M., Zajac, A., \& Stastny, P. (2018a). Endocrine response to high intensity barbell squats performed with constant movement tempo and variable training volume. Neuro Endocrinology Letters, 39(4), 342-348.

W ilk, M., Michalczyk, M., Golas, A., Krzysztofik, M., Maszczyk, A., \& Zajac, A. (2018b). Endocrine responses following exhaustive strength exercise with and without the use of protein and protein-carbohydratesupplements. Biology of Sport, 35(4), 399-405. https:/ / doi.org/ 10.5114/ biolsport. 2018.75754

W unsch, K.,W ursta, R., von Dawans, B., Strahler, J., Kasten, N., \& Fuchs, R. (2019). Habitual and acuteexerciseeffects on salivary biomarkersin responseto psychosocia stress. Psychoneuroendocrinology, 106, 216-225. https:/ / doi.org/ 10.1016/ j.psyneuen.2019.03.015 